Francisco Eduardo dos Reis Ferreira

Desenvolvimento de aplicações baseadas em serviços na Web Semântica

Dissertação de Mestrado

Carlos José Pereira de Lucena

Daniel Schwabe

Rio de Janeiro

Março de 2003 
Francisco Eduardo dos Reis Ferreira

\section{Desenvolvimento de aplicações baseadas em serviços na Web Semântica}

Dissertação de Mestrado

Dissertação apresentada ao Programade PósGraduação em Informática da PUC-Rio como reuquisito parcial para obtenção do grau de Meste em Informática. Aprovada pela comissão examinadora abaixo assinada.

Carlos José Pereira de Lucena

Daniel Schwabe

Rio de Janeiro

Março de 2003 
Francisco Eduardo dos Reis Ferreira

\section{Desenvolvimento de aplicações baseadas em serviços na Web Semântica}

Dissertação de Mestrado

Dissertação apresentada ao Programade PósGraduação em Informática da PUC-Rio como reuquisito parcial para obtenção do grau de Meste em Informática. Aprovada pela comissão examinadora abaixo assinada.

Prof. Carlos José Pereira de Lucena

Orientador

Departamento de Informática - PUC-Rio

Prof. Daniel Schwabe Orientador

Departamento de Informática - PUC-Rio

Profa. Simone Diniz Junqueira Barbosa

Departamento de Informática - PUC-Rio

Prof. Renato Fontoura de Gusmão Cerqueira Departamento de Infomática - PUC-Rio

Rio de Janeiro Março de 2003 
Todos os direitos reservados. É proibida a reprodução total ou parcial do trabalho sem a autorização da univsersidade, do autor ou dos orientadores.

\section{Francisco Eduardo dos Reis Ferreira}

Francisco Eduardo dos Reis Ferreira graduou-se em Engenharia de Computação pela PUC-Rio em dezembro de 2000 com excelência acadêmica. Participou e organizou diversos eventos nas áreas de engenharia de software e e-Business. Fundou a Milestone tecnologia da Informação em 2001. É reponsável pela área de tecnologia da empresa.

Ficha Catalográfica

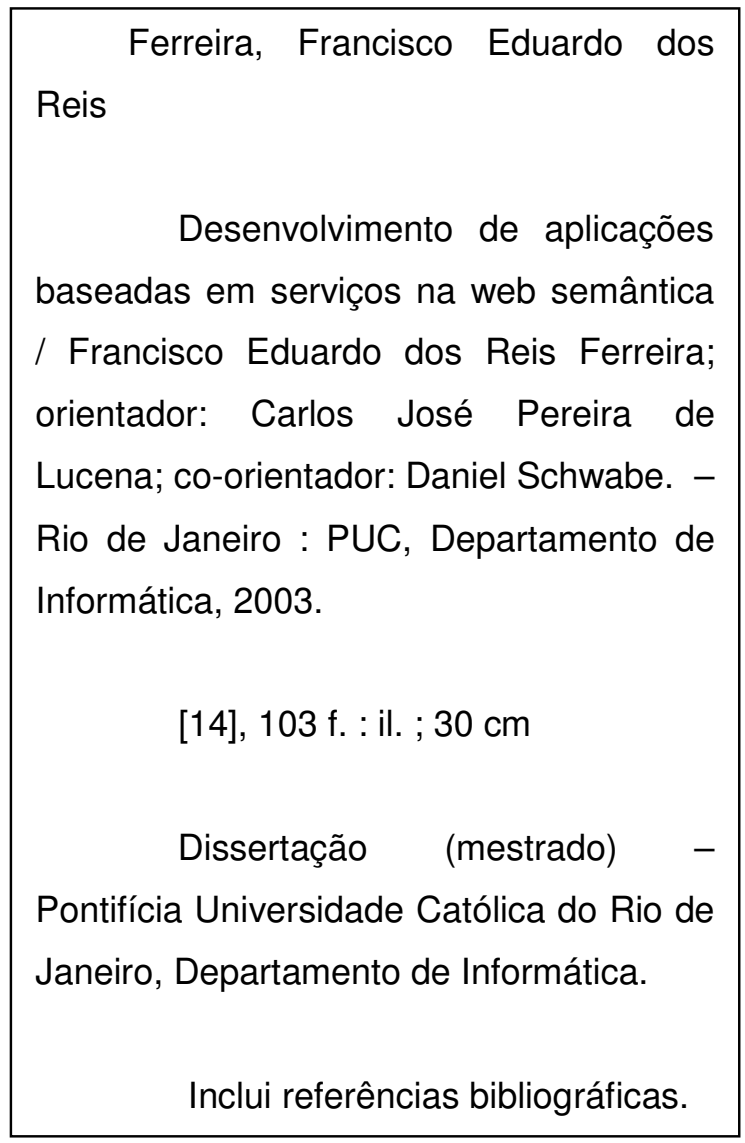

CDD:004 
Para os meus pais, Sueli e Francisco 


\section{Agradecimentos}

Escrever os agradecimentos é mais difícil do que redigir a dissertação. Não tenho dúvidas. Diversas pessoas colaboraram direta ou indiretamente para a realização do trabalho, com sugestões, idéias, críticas e opiniões. Outros contribuíram com amizade, carinho e afeto, provavelmente os ingredientes mais importnates para um bom trabalho. Temendo esquecer alguém, agradeço a todos que conviveram comigo nestes últimos dois anos. Gostaria de destacar algumas pessoas que foram especialmente importantes.

- Minha família, Francisco e Sueli, meus pais e minha irmã, Viviane, pela convivência quase diária e pelo carinho. Só vocês podem agüentar meus fins de semana de trabalho!

- Meus orientadores, Carlos Lucena e Daniel Schwabe, pelo apoio dado ao longo destes anos na PUC. O prof. Lucena tem um papel fundamental na minha formação, além de ser uma pessoa fantástica e admirada por todos que o conhecem. Daniel é um professor que passei a admirar com o tempo, com nossas intermináveis conversas sobre tese e informática. Orientador não é um chefe, é um amigo, em quem você confia e que está sempre pronto para ajudar nos momentos difíceis. Felizmente tive dois amigos fantásticos!

- Meus amigos, brothers e sócios Daniel Orlean e Cristiano Rocha, que acompanharam de perto todo o desenvolvimento do trabalho. Convivi com eles boa parte destes últimos dois anos e espero que continuemos juntos por muito tempo!

- Otavio "Pirulito" Silva, meu grande (literalmente) amigo da PUC, que também contribuiu enormemente no trabalho, além de infinitas noitadas, festas, churrascos e afins.

- Para todos os meus amigos que não entendem absolutamente nada (ou quase nada) de informática. Mas que estiveram presentes nos momentos de diversão ao longo destes últimos dois anos. Galera NaFolia!, Marcelão, pessoal do CSI, Humberto "fera do pasto", Silvio "japa”, Daniel de Brasília, primos e todos os 
outros que não me lembro agora. Galera da C961 não pode ser esquecida, mas vale ressaltar que eles entendem (muito) de informática.

- Todos os meus amigos da PUC: Alessandro, Viviane, Sardinha, Guga, Daflon, Fred (mais uma dose!), Paulo Rivéro, Tati (me companheira de trabalhos, uma gigante!), LF, Matheus, João, Leo Cunha, Anarosa, Christina Flach (Christinosa), Cláudio Baiano, Akeo, Pigatti, Davi, Fabão, Sergio Crespo, Ayrton e Clécio. Deve faltar gente, mas com certeza gosto de todos!

- Guga e Fred (mais doses!), pela ajuda efetiva na implementação da tese. Prof. Renato Cerqueira pela ajuda na API de coordenação.

- Finalmente, mas não menos importante, minha querida Vera. Você vai para o céu com certeza depois de tudo que eu aprontei nesses dois anos (com as melhores intenções, eu garanto). Foram aproximadamente 10.000 favores, prontamente atendidos com enorme competência. $\mathrm{O}$ que seria de nós, pobres alunos de mestrado, sem a Vera. Você é nota 10.

- Luis Fernando, obrigado pelo suporte. Prometo que vou manter os antivírus atualizados!

- A todos que eu eventualmente tenha esquecido. Sou péssimo para lembrar das pessoas nessas horas.

- À CAPES, CNPq e PUC-Rio, pelos auxílios financeiros concedidos, indispensáveis à execução deste trabalho. 


\section{Resumo}

Ferreira, Francisco Eduardo dos Reis; Lucena, Carlos José Pereira de; Schwabe, Daniel. Desenvolvimento de aplicações baseadas em Serviços na Web Semântica. Rio de Janeiro, 2003. 103p. Dissertação de Mestrado Departamento de Informática, Pontifícia Universidade Católica do Rio de Janeiro.

Este trabalho apresenta uma plataforma para aplicações baseadas em serviços. Esta plataforma foi concebida para dar suporte ao compartilhamento de informações serviços usando diferentes dispositivos. Através do uso de padrões abertos e de uma abordagem totalmente distribuída, Everyware permite que os usuários finais possam disponibilizar serviços sem necessidade de configuração ou administração. Estes serviços podem ser marcados semanticamente e integrados à Web semântica, o que permite que sejam processados automaticamente por máquinas. A plataforma ainda oferece uma arquitetura padrão para o desenvolvimento de aplicações e uma API para o desenvolvimento de mecanismos de coordenação de serviços que integra os diversos aspectos presentes em aplicações baseadas em serviços.

\section{Palavras-chave}

Web Semântica, Serviços; Serviços Web; Componentes de Software, Coordenação de Componentes, Peer-to-Peer; Ontologias 


\section{ABSTRACT}

Ferreira, Francisco Eduardo dos Reis; Lucena, Carlos José Pereira de (Advisor); Schwabe, Daniel (Advisor). Developing service-oriented applications on the semantic web. Rio de Janeiro, 2003. 103p. M. Sc. Dissertation - Departamento de Informática, Pontifícia Universidade Católica do Rio de Janeiro.

This work addresses issues on the development of service-oriented applications on the semantic web. It presents a platform conceived to support information sharing among different services accessed by different devices and hardware infrastructure. Using open standards and a totally distributed approach, Everyware allows users to publish their services without need of configuration and administration. Services can also be semantically tagged and integrated to the Semantic Web, so they can be easily processed by machines. Everyware platform offers a standard architecture to application development and an API to the development of coordination mechanisms. It integrates most concerns that are present in service-based applications.

\section{Keywords}

Semantic Web; Service; Web Services; Software Components; Component coordination; Peer-to-Peer; Ontologies 


\section{Sumário}

Lista de Figuras

Lista de Tabelas

1 Introdução

2 Aplicações baseadas em Serviços e Semântica 20

2.1. Componentes de Software e Serviços 21

2.1.1. WSDL 24

2.1.2. UDDI 25

2.1.3. SOAP (Simple Object Access Protocol) 25

2.1.4. Web Services vs. Internet Services 27

2.2. Composição de Serviços $\quad 27$

2.2.1. Composição de Web Services $\quad 29$

2.3. Web Semântica 30

2.4. Ontologias 31

2.5. Agentes de Software 33

2.6. Arquiteturas de implementação 34

2.6.1. Arquiteturas Peer-To-Peer 34

2.6.2. Sincronismo versus Assincronismo 35

2.6.3. Dispositivos de acesso à informação 36

2.6.4. Autenticação e Confiabilidade 37

2.7. Requisitos de aplicações baseadas em serviços no contexto da Web Semântica

3 Trabalhos Relacionados $\quad 40$

3.1. Sistemas Peer-To-Peer 40

3.1.1. JXTA 40

3.1.2. Groove Network 41 
3.2. Semântica em serviços 42

3.2.1. DAML-S 42

3.2.2. Web Services Modeling Framework (WSMF) 45

3.2.3. TAP 46

3.2.4. Retsina Calendar Agent 46

3.3. Serviços pessoais $\quad 47$

3.3.1. Net MyServices (HailStorm) 47

3.3.2. Apple .Mac ${ }^{\mathrm{TM}} \quad 48$

3.4. Composição de Serviços 48

3.4.1. BPEL 48

3.4.2. BTP 51

4 Estudos de Caso 53

4.1. Busca Semântica 53

4.1.1. Arquitetura da aplicação 55

4.1.2. Conclusões 56

4.2. Estudo de Caso: Calendário 57

4.3. Resumo dos Estudos de Caso 62

5 Everyware: Uma Arquitetura para Aplicações baseadas em serviços utilizando a Web Semântica 64

5.1. Princípio de Organização 64

5.2. Componentes 65

5.2.1. Provedor de Serviços leve 65

5.2.2. Framework de coordenação 66

5.2.3. Extensão para suporte à semântica nos serviços 71

5.3. Arquitetura 77

5.4. Questões de implementação e design 79

5.5. Os estudos de caso utilizando Everyware 81

5.5.1. Calendário 81

5.5.2. Busca Semântica 84

6 Conclusões e Trabalhos Futuros $\quad 87$ 


\section{Lista de Figuras}

Figura 1 - A Arquitetura para a Web Semântica proposta por Berners-Lee ..................17

Figura 2 - Definição de serviço no contexto de uma aplicação ......................................22

Figura 3 - Exemplo de mensagem SOAP .....................................................................26

Figura 4 - Exemplo de composição de serviços .....................................................................30

Figura 5 - Exemplo de uma descrição de serviço em DAML-S .....................................44

Figura 6 - Ontologia básica da aplicação de busca semântica ..........................................54

Figura 7 - Arquitetura da aplicação de busca (1) a aplicação de busca consulta serviços de ontologia para descobrir os conceitos aos quais o conceito procurado está associado. Em um segundo momento (2), os serviços de informação associados são consultados para obter referências para páginas web que possuam conteúdo relacionado ao termo procurado.........................................55

Figura 8 - O cliente Web do sistema de calendários baseado em serviços.....................59 Figura 10 - A representação de um compromisso utilizando a ontologia iCal definida

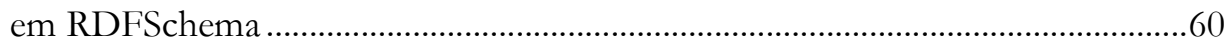

Figura 11 - Um compromisso representado na ontologia DAML Agenda..................61

Figura 12 - Fluxo de informação do Everyware LW. Um cliente de um serviço envia um pedido para um coordenador que invoca os serviços para executar um processo. Everyware LW funciona com um Proxy par o serviço de e-mail, processando requisições de serviço toda vez que o dono do serviço checa por email através de um cliente de e-mail comum .........................................................66

Figura 13 - Arquitetura geral do sistema em função dos componentes ........................67

Figura 14 - A classe Coordination Factory.........................................................................68

Figura 15 - A classe AbstractBus ................................................................................69

Figura 16 - A seqüência para tratamento de uma resposta de um componente...........70

Figura 17 - Design do Framework …………………................................................

Figura 18 - A diferença entre um serviço semântico e um serviço comum. Enquanto serviços comum recebe e envia informações sem nenhum tipo de representação que indique se significado, os serviços semânticos utilizam estruturas e ontologias para permitir inferência sobre a informação por máquinas. 
Figura 19 - Cabeçalho de arquivo WSDL incluindo o namespace de um esquema RDF.

Figura 20 - Importação dos esquemas utilizados pelo serviço.

Figura 21 - Definição do conteúdo de uma mensagem para um serviço semântico .74

Figura 22 - Informações de implantação de serviço..... .75

Figura 23 - Importação de namespaces. Não há necessidade de namespaces adicionais para os esquemas de marcação semântica...............................................75

Figura 24 - Definição das mensagens trocadas por um serviço comum em função de tipos básicos presentes em XML Schema ............................................................76

Figura 25 - Especificação de operação de um serviço comum. A ordem dos parâmetros faz parte da especificação da operação.

Figura 26 - Uma simples execução de um serviço de calendário. Depois de uma requisição, cada calendário individual é chamado e recupera informações relativas aos compromissos. O relógio próximo ao telefone celular da Carol ilustra o comportamento assíncrono desse serviço durante todo o processo de

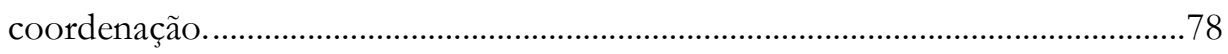

Figura 27 - As camadas do provedor Everyware e o conteúdo associado. ...................79

Figura 28 - Representaçã original - DAML Agenda .....................................................82

Figura 29 - Representação final - Hybrid iCal................................................................83

Figura 30 - Processo da aplicação de busca semântica .......................................................85 


\section{Lista de Tabelas}

